\title{
A EDUCAÇÃO FÍSICA QUE EU QUERO: CONTRIBUIÇÕES DA DISCIPLINA DE PRÁTICAS ESPORTIVAS NA REALIDADE DA ESCOLA ESTADUAL PLENA DAURY RIVA
}

\section{ARTIGO ORIGINAL}

SCHOENBERGER, Valdenir ${ }^{1}$

SCHOENBERGER, Valdenir. A educação física que eu quero: Contribuições da disciplina de práticas esportivas na realidade da escola estadual plena Daury Riva. Revista Científica Multidisciplinar Núcleo do Conhecimento. Ano 04, Ed. 07, Vol. 10, pp. 32-42. Julho de 2019. ISSN: 2448-0959

\section{RESUMO}

O presente estudo analisa a implantação da disciplina de Práticas Esportivas na Escola Estadual Plena Daury Riva, Juara - Mato Grosso. A proposta é desenvolver junto aos alunos atividades físicas associadas com regras desportivas, em um trabalho concomitante com a disciplina de Educação Física. A disciplina de Práticas Esportivas vem como uma base inicial para o $3^{\circ}, 4^{\circ}$ e $5^{\circ}$ anos do ensino fundamental (anos iniciais), e como uma base auxiliar no $6^{\circ}, 7^{\circ} 8^{\circ}$ e $9^{\circ}$ anos do ensino fundamental (anos finais). De forma aplicada, o desenvolvimento das aulas de Práticas Esportivas constitui-se em uma ação conjunta, perfazendo e auxiliando as aulas de Educação Física visto que contam com o envolvimento de professores e alunos no processo e estruturação de atividades desportivas, jogos lúdicos, construção e aperfeiçoamento do repertório motor, espirito de equipe, construção do senso moral, entendimento do "Outro" não como adversário, mas como ser presente e necessário para o pleno desenvolvimento do esporte. O presente estudo teve como objetivo fomentar uma discussão a respeito da importância das disciplinas de Educação Física e Práticas Esportivas no cenário da Escola Estadual Plena Daury Riva. Conclui-se que Educação

${ }^{1}$ Especialização em Gestão em orientação e Supervisão Escolar. Especialização em Educação Física Escolar, saúde e qualidade de vida. Graduação em Educação Física. 
Física e Práticas Esportivas são componentes de suma importância no caminhar acadêmico de todos os discentes, desta forma devem ser primadas de forma ininterrupta e integral no cenário escolar atual.

Palavras-chaves: Educação Física, práticas esportivas, esporte.

\section{CONSIDERAÇÕES INICIAIS}

Este relato de experiência tem como tema a implantação da disciplina de Práticas Esportivas, matéria esta, desempenhada de forma concomitante, mas não em separado da cadeira da base nacional curricular comum (BNCC) de Educação Física. O objeto aqui relatado caracteriza-se como ação desenvolvida na disciplina de Práticas Esportivas na Escola Estadual Plena Daury Riva na Cidade de Juara durante o período letivo de 2019. A disciplina de Práticas Esportiva tem em seu cerne a contemplação de todo o repertório cognitivo, corporal, afetivo, ético, estético, de relações interpessoais e da plena interação social, características estas fomentadas, estabelecidas e desenvolvidas por meio dos esportes, dos jogos, da ginástica, das lutas, das danças, entre outros.

A Escola Estadual Plena Daury Riva, instituição sem fins lucrativos, localizado na Avenida Paraná, №. 750 (E). Bairro Residencial Santa Terezinha, oferece Educação Integral, com uma parte diversificada nos componentes curriculares do $1^{\circ}$, $2^{\circ}$ e $3^{\circ}$ ciclos, que são os macro-campos: Atividades de Convivência, Hábitos Higiênicos e Alimentares; Atividades de Linguagem; Práticas Esportivas; Atividades Culturais e Artísticas; Atividades de Formação Pessoal e Social; Atividades de Matemática; Atividades de Mídias Digitais e Tecnológicas.

O desenvolvimento deste formato de aulas plenas vem de uma série de programas de governo que resultam em outros, os quais por vezes não possuem uma continuidade nem resultados efetivos. A educação de tempo integral desenvolvida na Escola Estadual Plena Daury Riva advém de um projeto que teve inicio como Programa Mais Educação (2015), Escola de Ensino Regular (2016 - 2017), 
transformando-se em Escola de Tempo Integral (2018) e culminou no atual modelo de Escola Plena (2019).

De forma aplicada, o desenvolvimento das aulas de Práticas Esportivas constitui-se em uma ação conjunta, perfazendo e auxiliando as aulas de Educação Física visto que contam com o envolvimento de professores e alunos no processo e estruturação de atividades desportivas, jogos lúdicos, construção e aperfeiçoamento do repertório motor, espirito de equipe, construção do senso moral, entendimento do "Outro" não como adversário, mas como ser presente e necessário para o pleno desenvolvimento do esporte. Por meio da participação conjunta Práticas Esportivas/Educação Física no processo de ensino-aprendizagem, a oportunidade de aproximar a teoria aprendida em sala de aula a uma aplicação prática de tais conteúdos no experimentar do contexto social.

Os discentes terão à possibilidade de vivenciar o pleno desenvolvimento esportivo, agregando toda uma gama de movimentos motores, prática de atividades lúdicas e situações de ações cooperativas dos jogos, resultando em um processo de agregação, reflexão, participação e propagação das atividades para fora dos muros da escola. Além da tomada de consciência, rumo ao fomento á atividade física e a promoção da saúde, formação de um senso crítico, participação cidadã e autonomia. O objetivo geral da disciplina é proporcionar aos alunos matriculados na escola uma atividade esportivo-educativa alicerçada à prática pedagógica progressista, resultando em cidadãos plenos para uma vida ativa e cooperativa em sociedade.

A proposta é desenvolver junto aos alunos da Escola Estadual Plena Daury Riva de Juara, atividades físicas associadas com regras desportivas, em um trabalho concomitante com a disciplina de Educação Física a qual é desenvolvida em sala de aula. Para tanto consideramos como eixos norteadores, as competências específicas da Educação Física (BRASIL, 2017, p. 221):

1. Compreender a origem da cultura corporal de movimento e seus vínculos com a organização da vida coletiva e individual. 
2. Planejar e empregar estratégias para resolver desafios e aumentar as possibilidades de aprendizagem das práticas corporais, além de se envolver no processo de ampliação do acervo cultural nesse campo.

3. Refletir, criticamente, sobre as relações entre a realização das práticas corporais e os processos de saúde/doença, inclusive no contexto das atividades laborais.

4. Identificar a multiplicidade de padrões de desempenho, saúde, beleza e estética corporal, analisando, criticamente, os modelos disseminados na mídia e discutir posturas consumistas e preconceituosas.

5. Identificar as formas de produção dos preconceitos, compreender seus efeitos e combater posicionamentos discriminatórios em relação às práticas corporais e aos seus participantes.

6. Interpretar e recriar os valores, os sentidos e os significados atribuídos às diferentes práticas corporais, bem como aos sujeitos que delas participam.

7. Reconhecer as práticas corporais como elementos constitutivos da identidade cultural dos povos e grupos.

8. Usufruir das práticas corporais de forma autônoma para potencializar o envolvimento em contextos de lazer, ampliar as redes de sociabilidade e a promoção da saúde.

9. Reconhecer o acesso às práticas corporais como direito do cidadão, propondo e produzindo alternativas para sua realização no contexto comunitário.

10. Experimentar, desfrutar, apreciar e criar diferentes brincadeiras, jogos, danças, ginásticas, esportes, lutas e práticas corporais de aventura, valorizando o trabalho coletivo e o protagonismo. 
Lembramos que a disciplina de Práticas Esportivas não se apresenta como uma forma de substituição ou compensação frente à disciplina de Educação Física, a qual vem sofrendo ao longo dos anos com perdas no número de aulas em sua grade curricular, perda de identidade frente aos discentes, desmotivação dos profissionais, falta de materiais esportivos, conteúdo ultrapassado e instalações inadequadas para o desenvolvimento da prática, ou como bem coloca (BETTI, 1992, p. 166):

"O que ficou claro para mim é que, apesar da deficiência da Educação Física na escola, deficiência esta percebida pelos alunos que filtram os acontecimentos com sua percepção, eles ainda conseguem sentir muito prazer em participar das aulas. Apesar da falta de comunicação professor $\mathrm{X}$ aluno, das desavenças com os colegas, do conteúdo que não muda, das condições das quadras e dos materiais, apesar de tudo os alunos, em sua maioria, continuam sentindo prazer em fazer as aulas [...]. Isto não justifica a falta de atenção para com a Educação Física de forma geral".

Assim, entendemos ser de suma importância o desenvolvimento da disciplina de Práticas Esportivas, pois nos dias atuais existe pouca ou nenhuma mobilidade por parte dos alunos fora das aulas de Educação Física, entendendo que a aprendizagem e o desenvolvimento da prática motora e desportiva se tornam cada vez mais urgentes e necessárias para uma crescente população sedentária, ou como bem salienta (FINCK, 2011, p. 22): "Tais pressupostos devem ser evidenciados na escola, no sentido de despertar nos alunos o interesse pela melhoria da qualidade de vida e, principalmente, em relação aos aspectos relacionados á manutenção da saúde".

\section{AFINAL, QUEM ÉS TU EDUCAÇÃO FÍSICA?}

Quando se apresenta a característica mais pura e primordial, o pilar balizador da disciplina de Educação Física, nos é apresentado o movimento (puro e simples) do homo sapiens, movimento este que propiciou a escalada do ser indefeso de garras, pelagem, presas, tamanho, velocidade, força e tantos outros atributos de sobrevivência frente às grandes feras que povoavam a terra juntamente conosco. 
Movimento este, entendido também como motricidade humana e que se faz presente até os dias atuais, propiciando mobilidade, locomoção e manuseio. $O$ homem se faz presente no mundo pelo movimento motor, ou como bem coloca (TOJAL, 2004, p. 153 - 154):

"A motricidade humana emerge da corporeidade como sinal de quem está no mundo para alguma coisa, isto é, como sinal de um projeto, e desta forma o homem é presença no espaço e na história, com o corpo, no corpo, desde o corpo e através do corpo, uma vez que basicamente não existe qualquer diferença entre motricidade e corporeidade, tendo em vista que ambas fazem parte da complexidade biológica do humano".

E desta maneira, o homem sobrepujou as demais formas de vida existente em nosso planeta, tornando-se assim o animal alfa, o ser no topo da cadeia alimentar. Posto este, que possibilitou sua vivência em sociedade e a construção do mundo moderno. Da mesma forma que o movimento humano transformou o homem em um ser superior dentro de uma sociedade civilizada e organizada, esta mesma sociedade transformou o homem - graças às comodidades cotidianas - em um ser preguiçoso e sedentário.

E é frente a este novo formato de vida pautada por uma total e completa falta de mobilidade que atualmente perdura no cotidiano social, que a disciplina de Educação Física se faz necessária no cenário escolar, desenvolvendo por meio de atividades: motoras, cognitivas, sociais e emocionais uma variada gama de exercícios com significância e perpetuação para a vida adulta de cada aluno.

"A Educação Física na escola deve ser uma disciplina inserida no contexto pedagógico e formativo da cidadania, com a finalidade de explicar a corporeidade, o sentido da qualidade de vida através de um estilo de vida ativo, que ofereça algumas vivências temáticas para que os alunos possam experimentar exercícios e práticas. A disciplina não pode estar calcada, nem ser justificada apenas na sua prática, mas sim, pela sua finalidade" (Confef, 2002). 
A disciplina de Educação Física vem como uma ferramenta lúdica e prazerosa no desenvolvimento dos jogos, da ginástica, das lutas, das danças e dos desportos, iniciando, desenvolvendo e aperfeiçoando em cada faixa etária do ser humano o aperfeiçoamento do movimento motor, um refinamento que perpassa a lateralidade, 0 equilíbrio, a motricidade ampla e a motricidade fina. Ou como salienta (FINCK, p. 26, 2011 apud TABORDA DE OLIVEIRA, 2003):

"Entendemos que Educação Física na escola se relaciona diretamente com a corporeidade e o movimento humano, que implica, portanto, uma atuação intencional sobre o homem como ser corpóreo e motriz, abrangendo formas de atividades físicas como o esporte, o jogo, a ginástica, as lutas, a dança, entre outras".

\section{DESAFIOS DA EDUCAÇÃO FÍSICA}

Embora a Educação Física seja uma das disciplinas mais apreciadas por uma vasta gama de alunos, ela ainda é pouco valorizada e, inclusive, passa por uma classificação, recebendo por vezes uma significância menor por parte do corpo docente e da sociedade em geral, tida como uma disciplina do correr e jogar bola.

"A Educação Física como área de conhecimento não tem sido capaz de "convencer" a sociedade suficientemente sobre a importância de sua presença no currículo escolar. A concepção ainda é a de que sua tematização na escola se resume apenas em correr, jogar bola, fazer ginástica e brincar" (FINCK, 2011, p. 25).

Isso se deve muito por parte do histórico da criação e do desenvolvimento da disciplina no ambiente escolar brasileiro por volta de 1920, as quais eram desempenhadas por soldados, repetidores de movimentos provenientes da vivencia militar. Com aulas embasadas pela simplificação do exercício físico, movimentos motores sem sentido aparente, além é claro do fazer por fazer. Aulas encabrestadas por uma ditadura do realizar o comando solicitado, crianças moldadas para uma vida de obediência e servidão a pátria. 
"[...] no Brasil a [Educação Física] foi pensada enquanto prática nas escolas com propósitos profiláticos, morais e culturais". Por falta até mesmo da formação adequada, muitos professores - chamados no passado de instrutores - aplicavam para crianças exercícios praticados nos quartéis "(Confef, 2002)".

Outro fator de grande desfavor para a disciplinada é que ainda não exista uma concordância dos profissionais sobre quais conhecimentos seriam mais significativos para serem desenvolvidos durante as aulas de Educação Física. Uma parcela dos professores defende o esporte como conteúdo principal a ser trabalhado nas aulas, principalmente aquele que os alunos mais gostam; outra parcela defende a difusão de conteúdos que abordem assuntos pertinentes à saúde, alimentação e qualidade de vida; e existem aqueles que defendam que a disciplina deva tratar de questões sociopolíticas (FINCK, 2011).

Muitas aulas são embasadas na prática pela prática, com pouca reflexão sobre o significado da disciplina, ou da interação do exercício físico e seus benefícios na manutenção corporal para o pleno desenvolvimento da qualidade de vida do cidadão (Confef, 2002). Esbarramos ainda nas aulas padronizadas nas competições, atividades desenvolvidas visando jogos escolares entre escolas, as quais selecionam os mais habilidosos e exclui os menos habilidosos, ou, ainda, quando a aula torna-se monótona e previsível, fazendo com que alguns alunos se excluam das mesmas, pois nela são desenvolvidas somente as técnicas e táticas do esporte, o qual visa o puro rendimento e não a inclusão e participação de todos, existe ainda aqueles que desenvolvem as atividades da forma que desejam ou querem (FINCK, 1995).

Existe ainda a falta de uma definitiva efetivação do discurso pró Educação Física e seus benefícios, uma forma clara de por em prática toda a cientificidade embasadora da disciplina que permeia os recantos universitários e que esta longe de chegar às quadras escolares, ou como bem salienta (FINCK, 2011, p. 23):

"Embora a Educação Física tenha se desenvolvido nos campos científico, epistemológico e acadêmico, bem como acompanhado a 
educação nas mudanças sociais e políticas, as quais foram traduzidas num discurso que supervaloriza essa área, todo esse processo ainda é muito contraditório, principalmente porque tal discurso não chegou a influenciar definitivamente a prática pedagógica".

Muito embora a disciplina de Educação Física seja por vezes embutida de deveres e obrigações, e pouco tenha se manifestado para exercer tais nuances, é ainda uma disciplina versátil e prazerosa. É aquela que lembra o ser humano dos prazeres e desejos do brincar, do jogar, do ser o homo sapiens em sua essência mais pura, o homem em movimento, o homem no movimento e o homem para o movimento.

\section{EDUCAÇÃO FÍSICA E PRÁTICAS ESPORTIVAS}

A escola por via de regra é um dos primeiros locais que proporcionam o contato da criança com a prática esportiva, isso se dá ou por falta de locais que permitam seu desenvolvimento extraescolar como: parques, praças e clubes, ou pelo fato da instituição escolar ser um local habitual onde os discentes se sentem acolhidos e prontos para o pleno desenvolvimento do esporte (SANTOS; SIMÕES, 2007). A significância do esporte na escola advém do principio de ser uma das vertentes da Educação Física, e também por difundir e promover a cultura, tornando o acesso democrático de todos os alunos a esta forma de conhecimento (PAES, 2002).

Vale lembrar aqui que o desenvolvimento das atividades da disciplina de Práticas Esportivas propiciadas como vertente da disciplina de Educação Física vem como uma forma de iniciação esportiva pedagógica, onde o aluno terá acesso a uma variada gama de atividades esportivas baseadas em uma cultura lúdica, agregadora e integradora, ou como bem salienta (FINCK, 2011, p. 26 - 27):

"Por isso, deve contribuir de maneira significativa com a formação e desenvolvimento dos alunos, oportunizando momentos pedagógicos de modo que possam interagir por meio da vivência de diversas situações de ensino aprendizagem. Estas devem abranger inúmeros movimentos que envolvem muito mais do que atos motores, sendo impregnadas de 
significados, expressividade, alegria e prazer. A vivência dessas situações oportuniza o desenvolvimento não só de habilidades, mas de competências importantes para uma melhor convivência em grupo, como a capacidade de compartilhar, trocar, ouvir e aprender uns com os outros. À medida que essa interação acontece, o aluno estará mais motivado a participar das aulas, realizando atividades físicas e esportivas que o fazem superar seus limites, ampliando cada vez mais suas experiências e seu conhecimento".

Outro fator de suma importância dentro do desenvolvimento da disciplina de Práticas Esportivas é sua escalonagem de conteúdos, estes são embasados nos conteúdos desenvolvidos na disciplina de Educação Física, mas de forma diversificada, ou seja, como uma forma de iniciação esportiva, destacando movimentos basilares em cada modalidade. Desta forma os discentes terão a apresentação da modalidade durante as aulas de Educação Física de uma forma mais ampla, desenvolvimento do esporte com regras estabelecidas, correção do gestual, noções de arbitragem e competições, já dentro da disciplina de Práticas Esportivas, os mesmos terão a apresentação de fundamentos dos esportes e sua prática vivenciada de forma lúdica, agregadora e inclusiva, ainda neste sentido (FINCK, 2011, p. 32 - 33):

"Os objetivos em relação aos conhecimentos dessa área - esporte, jogos, dança, lutas, ginástica - devem ser diferenciados em relação aos objetivos destes mesmos conhecimentos numa perspectiva profissional. Por outro lado, a atividade física e esportiva no contexto profissional deve ser considerada e abordada na escola, a fim de que os alunos tenham um conhecimento mais amplo dessas manifestações da cultura corporal de movimento, podendo, assim, fazer uma leitura competente e crítica do contexto. Seja qual for o objetivo de conhecimento no processo de ensino aprendizagem, a individualidade e as características dos alunos devem ser consideradas, assim como as potencialidades valorizadas e as limitações respeitadas, em todas as dimensões: 
cognitiva, corporal, afetiva, ética, estética, de relação interpessoal e de interação social".

Todo este processo de iniciação do esporte durante as aulas de Práticas Esportivas tem sua função derradeira no desenvolvimento das aulas de Educação Física, pois servirá de anteparo para que a criança tenha na idade certa atividades que por vezes são ou atrasadas ou adiantadas. Logo este planejamento desenvolvido e posto em prática na base de uma disciplina terá sua culminância esportiva em outra, fazendo com que o esporte seja interiorizado primeiramente como uma forma de movimento lúdico e depois como uma forma esportiva para a vida toda. Ainda complementando (FINCK, 2011, p. 30):

"Para tanto, é necessário que os conhecimentos tematizados nas aulas sejam contextualizados e abordados de forma mais atrativa e próxima das atividades físicas e esportivas que os alunos apreciam e praticam [...]. Assim, eles terão acesso a conhecimentos mais aprofundados cientificamente, o que Ihes possibilitará ir além do nível de informação do senso comum, diferenciando o espaço da escola dos demais em grau de importância".

Quando observamos outra importante significância que a disciplina de Práticas Esportivas trás para os discentes e para uma futura caminhada do esporte que será ofertado no decorrer dos anos letivos, é a forma como este deve ser abordado e organizado. Pois as manifestações esportivas na vida de cada criança devem ser diversas, indo desde as orientações educativas das práticas escolares esportivas, passando pela prática do esporte na escola até a institucionalização dos jogos estudantis (SIMÕES, 1999).

\section{CONSIDERAÇÕES FINAIS}

Podemos perceber uma possível luz no fim do túnel quando pensamos em uma nova vertente paralela á disciplina de Educação Física. A disciplina de Práticas Esportivas vem como uma base inicial, pois é desenvolvida no $3^{\circ}, 4^{\circ}$ e $5^{\circ}$ anos do ensino 
fundamental (anos iniciais), séries que não são contempladas pelo desenvolvimento da disciplina de Educação Física e como uma base auxiliar no 6ํㅜ , $7^{\circ} 8^{\circ}$ e $9^{\circ}$ anos do ensino fundamental (anos finais). Como já foi preconizada ao longo do texto, a disciplina de Práticas Esportivas é uma dicotomia da Educação Física, vertente que possibilita a inclusão de crianças em atividades físicas socializadoras, todas embasadas em fundamentos solidários, integradores, inclusivos e participativos. As aulas são voltadas para o movimento pré-dirigido, ou seja, uma forma de atividade que possibilita o protagonismo, pois os mesmo não são balizados por regras e fundamentos esportivos.

Consideramos o esporte - um sistema dinâmico e complexo - um dos principais palcos para uma completa execução e continuidade da caminhada escolar. Foi graças aos pressupostos aqui formulados e apresentados, cujas vertentes sugerem significantes aspectos a considerar sobre as disciplinas acima citadas (Educação Física - Práticas Esportivas). Concluímos que o debate sobre a valorização das mesmas e sua significância no decorrer da construção do homem devem estar fortemente pautadas em espaços formativos escolares, tanto na formação inicial quanto na continuada, propiciando uma reestruturação social enraizada por valores de solidariedade e de uma plena convivência em sociedade.

\section{REFERÊNCIAS}

BETTI, I. C. R. O prazer nas aulas de Educação Física: a perspectiva discente. 1992. Dissertação (Mestrado em Educação) - Universidade Estadual de Campinas, Campinas, 1992.

BRASIL, Ministério da Educação. Base Nacional Comum Curricular: Educação Infantil e Ensino Fundamental. Brasília: MEC, 2017.

CONFEF - Conselho Federal de Educação Física. Educação Física escolar. Revista EF, Rio de Janeiro, n. 5, dez. 2002. Disponível em: http://www.confef.org.br/extra/revistaef/show.asp?id=3457. Acesso em: 10 de março de 2019. 
FINCK, Silvia Cristina Madrid. A educação Física e o desporto na escola: cotidiano, saberes e formação. $2^{\circ}$ ed. Curitiba: Ibpex, 2011.

FINCK, S. C. M. Educação Física e Esporte: uma visão na escola pública. 1995. Dissertação (Mestrado em Educação) Universidade Metodista de Piracicaba, Piracicaba, 1995.

PAES, R. R. A pedagogia do esporte e os jogos coletivos. In: De Rose D (Org.). Esporte e atividade física na infância e na adolescência: Uma abordagem multidisciplinar. Porto Alegre: Artmed, 89-98. 2002.

SANTOS, Ana Lúcia dos; SIMÕES, Antônio C. A influência da participação de alunos em práticas esportivas escolares na percepção do clima ambiental da escola. Revista Portuguesa da ciência e do desporto. Ed. v. 7 no 1. p. 26 - 35. 2007. Acesso em 15 de março de 2019: https://rpcd.fade.up.pt/_arquivo/artigos_soltos/vol.7_nr.1/1.03.pdf

SIMÕES A. C.; BOHME, M. T. S.; LUCATO, S. A participação dos pais na vida esportiva dos filhos. Revista Paulista de Educação Física 13: 34-35. 1999.

TABORDA DE OLIVEIRA, M. A. Práticas pedagógicas da Educação Física nos tempos e espações escolares: a corporeidade como termo ausente? In: BRACHT, V.; CRISÓRIO, R. (Coord.) A educação Física no Brasil e na Argentina: identidade, desafios e perspectivas. Campinas: Autores Associados, 2003.

TOJAL, J. B. A. G., Da Educação Física à Motricidade Humana - A preparação do profissional. Lisboa/Portugal: Editora Piaget, 2004.

Enviado: Março, 2019.

Aprovado: Julho, 2019. 